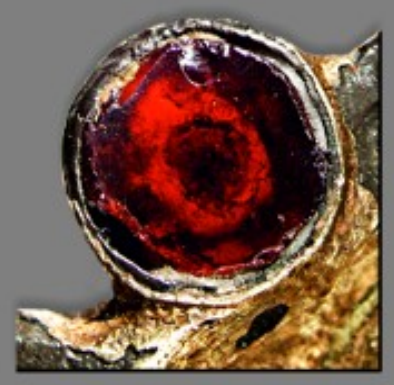

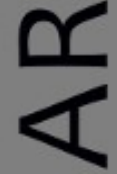

$\sim$

ш
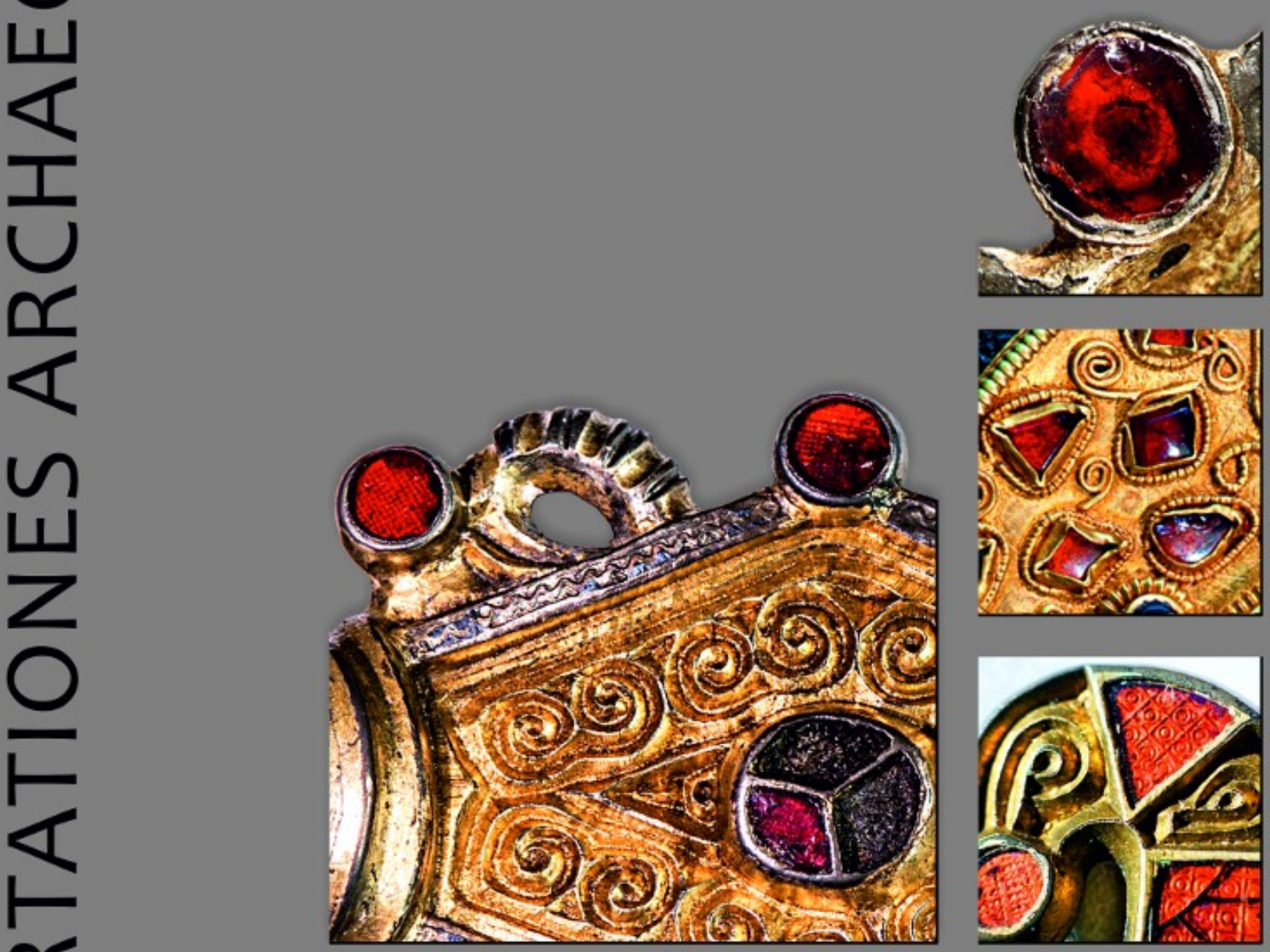

E

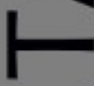

œ

山

n

ก

$\overline{0}$
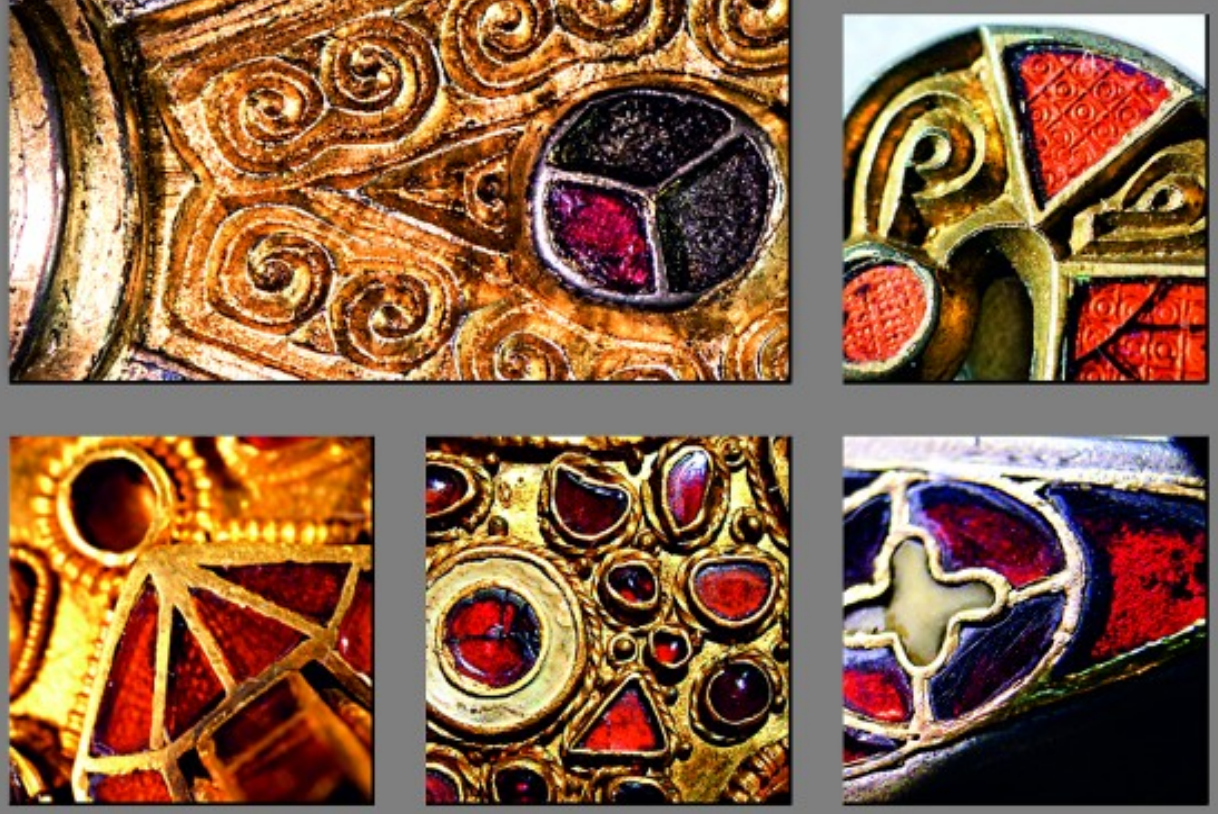

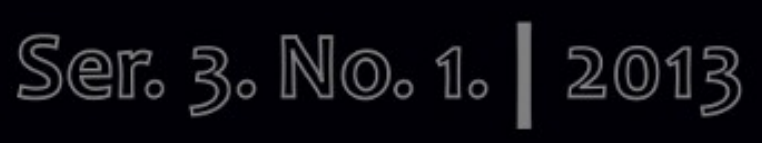




\section{Dissertationes Archaeologicae ex Instituto Archaeologico}

Universitatis de Rolando Eötvös nominatae Ser. 3. No. 1.

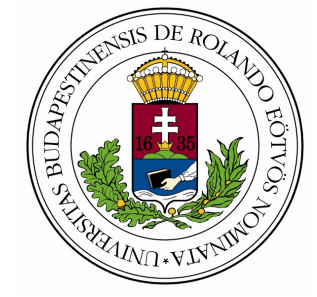

Budapest 2013 
Dissertationes Archaeologicae ex Instituto Archaeologico

Universitatis de Rolando Eötvös nominatae

Ser. 3. No. 1.

Editor-in-chief:

DÁvid BARTUS

Editorial board:

LÁSZLÓ BARTOSIEWICZ

LÁSZLÓ BORHY

ISTVÁN FELD

GÁBOR KALLA

PÁL RACZKY

Miklós SzABÓ

TIVADAR VIDA

Technical editors:

DÁvid BARTuS

GÁBOR VÁCZI

ANDRÁs BöDŐcs

Proofreading:

Zsófia KondÉ

SzILvia SzÖLlősI

Available online at http://dissarch.elte.hu

Contact: dissarch@btk.elte.hu

\section{$\underline{\text { PKP }}$ \\ PUBLIC \\ KNOWLEDGE \\ PROJECT}

(C) Eötvös Loránd University, Institute of Archaeological Sciences

Budapest 2013 


\section{Contents}

\section{Articles}

Melinda TORBÁGYI - István VIDA

The coin hoard of Abasár

Anikó BózsA

21

Roman mirrors from a private collection in the Hungarian National Museum

Lajos JuHÁsz

45

The Biesheim cameo - a reinterpretation

\section{Methods}

Péter CsIPpÁN

$A z$ állatcsont, mint információhordozó leletanyag

Kata DÉvAI

Terminológiai alapfogalmak régészeti korú üvegtárgyak elemzéséhez

Lőrinc TimáR - Zoltán Czajlik - Sándor Puszta - Balázs Holl

$3 D$ reconstructions using GPR data at the Mont Beuvray

\section{FIELD REPORTS}

Zsolt MESTER

Excavation at a new Upper Palaeolithic site of the Eger region (Northern Hungary)

László BORHY - Dávid BARTus - Emese SzÁmadó

Short report on the excavations at Brigetio (Szőny-Vásártér) in 2013

Dénes HulLÁm - Zsófia RÁcz

Report on the participation of the Eötvös Loránd University at the Wielbark Archaeological Field School in Malbork-Wielbark, Poland

Gábor VÁczi - Dávid BARTus

Short report on the excavations at the site Makó - Igási Ugar

Maxim MoRdovin

Short report on the excavations in 2013 of the Department of Hungarian Medieval and Early Modern Archaeology (Eötvös Loránd University, Budapest)

\section{THESIS ABSTRACTS}

Kitti KÖHLER

Biological reconstruction of the Late Neolithic Lengyel Culture 
Cultural connections and interactions of Eastern Transdanubia during the Urnfield period

Orsolya LÁNG

Urban problems in the civil town of Aquincum: the so-called „northern band”

Nikoletta SEY

Questions of bronze workshops in Roman Pannonia

Kata DÉvaI

Glass vessels from Late Roman times found in graves in the Hungarian part of Pannonia

Eszter HORvÁTH

Gemstone and glass inlaid fine metalwork from the Carpathian Basin:

the Hunnic and Early Merovingian Periods

Gergely SzEnTHE

Vegetal ornaments in the Late Avar decorative art

Péter LANGó

Relations between the Carpathian Basin and South East Europe during the 10th century.

The evidence of the minor objects

Ciprián HoRvÁTH

The Cemeteries and Grave Finds of Györ and Moson Counties from the Time

of the Hungarian Conquest and the Early Árpádian Age

András Sófalvi

The border- and self-defence of Szeklers from the Medieval Age till the Age of Principality.

Castles and other defence objects in the settlement history of Udvarhelyszék 


\title{
Roman mirrors from a private collection in the Hungarian National Museum
}

ANiKó BózsA

Ferenczy Museum

Szentendre

aniko.bozsa@femuz.hu

\begin{abstract}
In 2002, the Hungarian National Museum obtained by condemnation and adjudication a private metal collection from Kaposvár with more than 10,000 objects, among them numerous Roman mirror fragments. Unfortunately there is no information on the provenance of the finds, but it is possible that they have a south Pannonian origin. The aim of the present paper is the description and classification of the mirror fragments as well as their comparison to the Pannonian and Italian types and forms from other Roman provinces.
\end{abstract}

The mirror types from the entire Roman territory are considerably uniform regarding forms, find complexes and dating. In spite of this there are forms in certain territories - e.g. in Pannonia - which are specific in some elements. The appearance of these shows no tendency, and they are not very numerous. Because of the few publications dealing with Roman mirrors, it cannot be certainly declared that one type can only be found in one place or one period, but maybe these are among which the local products can be searched for.

Although the 87 mirrors from the Kaposvár collection are all fragmentary, they can be classified on the basis of their characteristic features. By these the following typological groups were created, based upon formal criteria. The types can be integrated into the well-known Pannonian mirror types and also forms from other parts of the Roman Empire. ${ }^{1}$

\section{Rectangular mirror fragments (Cat. 1-7)}

The six rectangular mirror fragments have a similar design: they are made of an undecorated metal lamina of which only one side is refined and polished while the other side is rough and matte. The edges are usually diagonal and unfinished.

The rectangular, usually palm-sized mirror plates are rare in Pannonia. Most pieces were unearthed in Arrabona, but the form can be found in the archaeological heritage of all larger Roman settlements of the province.

This mirror type is popular and characteristic in the entire Roman Empire, although its number cannot match that of the circular type. Its origin is uncertain, it could have appeared in the Hellenistic period ${ }^{2}$ but the rectangular mirror form has certainly been in general usage from the 1 st century $\mathrm{AD} .^{3}$

1 The typology of Roman mirror types was created by G. Lloyd Morgan on the basis of objects from the north-western provinces and Italy (LLOYd MoRGAn 1981a). The few following publications applied this tipology by classifying mirrors from a certain area, e.g. K. Kelbert who collected objects from Savaria in her article (KeLBERT 2007).

2 Lloyd Morgan 1977a, 233.

3 Lloyd Morgan 1981, 3. 
Some pieces from burials in Hellenistic find contexts in Pantikapaion and Thessaly have been published by M. Treister, along with three bronze plates from Myrna which he assumed to be mirrors. ${ }^{4}$ Here he also observed a rectangular mirror in the hands of a terracotta Eros statuette. ${ }^{5}$ Besides, the combing scene of the well-known wall painting of the Villa dei Misteri documents that rectangular mirrors were already in use in the middle of the 1st century $\mathrm{BC}$ in Italy. According to $\mathrm{M}$. Treister the Romans probably adopted the mirror type in Asia Minor from the Augustean era onward. ${ }^{6}$ Along with other mirror types, there is no information about when the production of this type ceased. Neither M. Treister nor G. Lloyd Morgan assumes that its production continued in the 2nd century AD. ${ }^{7}$

Rectangular mirrors were produced in various centres; G. Lloyd Morgan assumed a local workshop to be in Nijmegen where the type was found in especially high numbers. ${ }^{8} \mathrm{M}$. Treister divided the mirrors into three size categories, based on length: longer than $12,5 \mathrm{~cm}$, between $12,5 \mathrm{~cm}$ and $10,5 \mathrm{~cm}$ and smaller than $10,5 \mathrm{~cm}$. According to his observations the smaller rectangular mirrors are usual in the north of Italy, along the Sava River and the Lower Rhine, while the larger ones are frequent in the Pontic area. ${ }^{9}$

Since typically only one side of the mirrors is polished and the edges are unfinished, it is suggested that these were kept in a wooden frame or box. In some cases, this is proved by in situ organic materials. ${ }^{10}$ Correlating to these observations the rectangular mirrors are frequently interpreted as framed table-, pocket- or parietal mirrors as well as ones belonging to cosmetic boxes. G. Lloyd Morgan found it possible that these mirrors belonged to metal cosmetic boxes. ${ }^{11}$ However this is not obvious as no special cosmetic boxes are known from the Roman period. For the clear differentiation we use this term to identify the metal laminae with a hemispherical container. To the more complex types another rectangular case is attached as well and they have an extractable top-slab which is similar to rectangular mirrors in form, but thinner. G. Lloyd Morgan published a top-slab of this kind the backside of which she defined as a mirror. In this case the same lamina served for both functions, it was not necessary to attach another mirror-plate to it. ${ }^{12}$ It should be mentioned that no other examples are known where the slabs were used as mirrors. If we assume that a second metal lamella was fitted to the interior side of these top-slab laminae - by the way, no such example is known in the Roman Empire - these would make the moving of the slab more difficult. Also, these kinds of top-slabs are smaller than the smallest rectangular mirrors. The other Roman container type used for carrying cosmetics was the so called "medicine box". Its small compartments are also covered by a top-slab. These could serve as surfaces for fixing mirrors as well, but no examples of this object are known in the Roman Empire. Therefore it is most probable that the cosmetic boxes belonging to rectangular mirrors were made of organic materials.

4 Treister 1994, 417, Fig. 2.1-3.

5 Treister 1994, 417, Fig. 2.4.

6 Treister 1994, 417.

7 Lloyd MORgan 1981, 3.

8 Lloyd MORgan 1981, x.

9 TREISTER 1994, 417.

10 Lloyd Morgan 1981, 4, 2 iii; Simonett 1941, 45-46, tomb 4, no. 1; Lloyd Morgan 1981, 3 , note 1.

11 Lloyd Morgan 1977a, 233.

12 Lloyd Morgan 1981, 83. 
Rectangular mirrors are known from the period between the second half of the 1st century $\mathrm{AD}$ and the end of the 2nd century $\mathrm{AD}$ in Pannonia. There are at least three terracotta moulds for casting rectangular mirrors among the unpublished material of the bronze foundry of Vindobona.

\section{Undecorated disc mirror fragments (Cat. 8-18)}

Disc mirror fragments are represented in the collection in higher numbers than rectangular mirrors. The fragments belonging to this group are slightly convex, undecorated, their convex side is polished, the other side is unfinished and matte. Similarly to the rectangular ones, some of these have unfinished and diagonal edges.

The undecorated disc mirrors represent the simplest and most common type in the entire Roman Empire. Because of the different workmanship of the two sides it is possible that the discs were fitted into wooden or bone frames or boxes. This is not inevitable, but an example is known from Pannonia: a disk mirror with a $2 \mathrm{~cm}$ wide wooden frame held together by rivets and bands was found in Intercisa. ${ }^{13}$ The unfinished edges could be another sign of the supposed frame or box, but the piece from Intercisa contradicts this: the edges of the mirror disk are regular and finished. Frames were also made of more lasting materials: mirrors in coloured terracotta frames in various forms are known from Syria. ${ }^{14}$ Signs of soldering can be seen on some mirrors' reverse side from Pannonia, this phenomenon implies that the mirror discs were not used by themselves.

It should be mentioned that although in this paper all undecorated disc mirror fragments were classified into the same group, it is not sure that these actually belonged to undecorated disc mirrors. Apart from this type the fragments could belong to undecorated hand mirrors as well. In these cases the fragments originate from those parts of the mirror discs where no special elements like the sign of the soldering, etc. are visible.

Undecorated disc mirrors are usually published from find contexts dated to the 1st and 2nd century $\mathrm{AD}$, but one example was unearthed in a burial from the first part of the 4th century $\mathrm{AD}$ as well. ${ }^{15}$ According to J. Istenič the type could have appeared in the provinces already in the La Tène D period. ${ }^{16}$ In Pannonia, most of the few datable pieces were buried in the second part of the 1st and the 2nd century $\mathrm{AD}$, however they still appear in burials from the 3rd century AD.

\section{Disc mirrors decorated with a concentric line beyond the edge (Cat. 19-22)}

Four mirror fragments of different workmanship were classified into this group. Two of them belong to a specific type, while the rest are at present without analogies among the Roman finds outside of this territory.

Lathe turned concentric circles are typical decoration elements on Roman mirrors, but the pieces in this group must be separated from the more representative mirror types because on them the incised line(s) appear only in a certain place and only on one side. 
The Cat. 19-20. pieces are fragments of a special mirror type. The slightly convex disc type decorated with one concentric circle incised $0.5 \mathrm{~cm}$ from the rounded-off edge is known from Pannonia as well as the north-western provinces and Italy. Originally handles were attached to the discs, but this can usually only be determined by the traces of solder and the imprint of the foot of the handle on the reverse side. The casserole-loop like decorated or undecorated handles with round or oval cross-section were attached at two points across the non-reflecting side of the mirror discs; unfortunately they remain very rarely. This mirror type is related to G. Lloyd Morgan's "a" subgroup of the "Corstopitum"-X type including the simplest pieces. ${ }^{17}$ As not all Pannonian pieces had imprints of the foot of a handle or other marks on the non-reflecting side of the mirror discs, it is imaginable that examples of this type existed without handles as well, but it is also possible that the observation was simply ignored in previous publications. The patinated thawing-spot on the reverse side of the Cat. 19. fragment is not definitely a mark of a handle.

The type can be dated mainly to the 2nd and 3rd centuries in Britannia, Germania and Gallia. The dating of pieces from Pannonia is similar; mirrors are usually found in contexts dated to the 2nd and 3rd centuries. It is important to note that - as in the case of the previ ous type - this mirror disc form is also known with an unusual vertical handle. ${ }^{18}$

The other two mirror fragments have unusual workmanship, no analogies of them are known.

\section{Disc mirrors with incised geometric pattern (Cat. 23-29)}

Incised decoration consisting of simple or more complex geometric elements can be found on this type of mirror discs. The patterns are placed to fields separated by concentric lines. The most specific decoration element in the collection is the dot-and-circle.

This decoration is different from the patterns on typical Roman hand mirror discs which emerged from Hellenistic antitypes. The type is frequent in the north-western provinces as well as the Balkan-peninsula and Italy. In Pannonia only eight pieces were known up to this day, but their number almost doubled thanks to the collection presented in this paper. The fragments can be classified into Lloyd Morgan's "Corstopitum-X" group. The Cat. 23-26. pieces belong to the "Xb" subgroup of which the characteristic feature is that the patterns on the reverse side of the discs consist of dot-and-circle motifs. Among the drawings published by G. Lloyd Morgan to present examples of the "Xb" subgroup there are analogues of the Cat. 23. and Cat. 26. fragments, but unfortunately no data on the origin is given. A rear loop handle belongs to this type of mirror discs, but no complete specimen was found in Pannonia up to this day.

The decorations of the other three fragments are more complex or have different character than the previous ones. The filling of patterns with dense bevelled lines (Cat. 29) and the rosettes are frequent elements on specimens from Pannonia as well as Moesia. ${ }^{19}$ These motifs also appear on the pieces classified by Lloyd Morgan to the "Xc" subgroup. The complex decoration raises the Cat. 28. fragment to the most beautifully and densely decorated mirrors

17 Lloyd MORgan 1981, 95.

18 CÜPPERS 1983, 275, 239.

19 KRUNIČ 2000, Nr. 38, T.4/38. 
of which only a few pieces are known from Italia, Germania, Britannia and Pannonia. Despite the similar elements of the decoration, no two identical pieces can be found among them.

The mirrors with incised decoration concentrate most densely in Germania, with a workshop assumed in Nijmegen. ${ }^{20}$ The pieces originate from the 1 st to the 3rd centuries AD, but mainly from the 3 rd century. ${ }^{21}$ Of the eight mirror discs found in Pannonia, only two examples have known find contexts. The first was found in the Roman cemetery at Paragváry street in Szombathely (Savaria), used between the Flavian Age and the middle of the 2nd century AD. The second piece was found in a burial of the cemetery of Százhalombatta (Matrica) dated terminus post quem by a coin of Domitianus. ${ }^{22}$

\section{Disc mirrors with turned concentric ribs and lines (Cat. 30-31)}

The only decoration on these mirror fragments consists of turned concentric circles on one or both sides of the discs. The turned lines are more dense on the reverse of the mirrors while on the reflecting side they only run along the edge.

These concentric turned ribs appear on the most specific Roman hand mirror-type: the disc mirrors with a separately made, soldered-on vertical handle (Fine Type Hand Mirrors) ${ }^{23}$ The handle could be a simple rod or multiple rods consisting of baluster formed elements or single or multiple loop formed elements. The former were more popular, and only this type is known in Pannonia up to this day. Forms, elements and the set-up of the handles will be discussed in detail in the adequate subsection of the paper. The discs frequently turn up without handles, but the traces of solder on the reverse side hint to the existence of a handle.

Only a few disc mirrors with turned concentric lines exist in Pannonia. These are usually very simple, heavy, relatively thick, the arrangement of the lines and ribs are repetitive. Compared to these, the mirrors discs from the western part of the Empire are more facile, more elegant and the decoration is more diverse. According to Lloyd Morgan the hand mirrors with turned lines were made and used in the 1st century AD and served as a base for the hand mirrors with a border of holes (discussed in the next chapter), the hand mirrors with radiate border (Lloyd Morgan "Group L") as well as the mixed type: mirror discs with a border of holes and jagged edge (Lloyd Morgan "Group M"). ${ }^{24}$ The type was used in the same period as other mirror types in Pannonia. Based on the few pieces that turned up in datable context, this was between the 1st and the 2nd centuries AD.

\section{Hand mirrors with a border of holes on the disc (Cat. 32-48)}

Reflecting the popularity of this type of hand mirrors in the whole Roman Empire, the number of fragments belonging to the type is the highest compared to that of other types in the collection. The discs are decorated with a border of small, circular, drilled holes and turned concentric ribs and lines. The vertical handles may have a grip consisting of baluster-formed elements as well as loops. The handle and the disc usually turn up separated, but the handle

\footnotetext{
20 Lloyd Morgan 1977b, 338.

21 Lloyd Morgan 1981, 95.

22 TOpÁL 1981, 21.

23 Lloyd Morgan 1981, 37.

24 Lloyd Morgan 1981, 44.
} 
has very definite traces on its surface: traces of solder, discoloured imprints, more vigorous corrosion or patina at the spot of the disc support where the border of holes is also interrupted (e.g. on the Cat. 35. fragment exactly this part is preserved). The turned concentric circles are concentrated on the reverse side, they appear on the reflecting side either along the border of holes or along the edge. Their placement is variable, but especially in Pannonia, there are some pieces similar in construction. The centre of the disc and the concentric circles is always accentuated; the disc is frequently moderately convex. The holes are situated usually in equal distance from each other, but in some cases the distance grows either half a centimetre, however this is not typical.

The mirrors with a border of holes represent the most popular and widespread mirror type in the Roman era. According to K. Roth-Rubi they were cheap and common articles for personal use, accordingly they were mostly made of copper alloy. ${ }^{25}$ The earliest examples in silver are known from Italy, the production may have been concentrated in the Cisalpine cities during the first half of the 1st century AD. ${ }^{26}$ Later, in the 1st and 2nd centuries they became widely used in the provinces as well. There is no information about when the production ceased because the pieces that were buried in the latest period may have been in use through more generations. The origins of the border of holes decoration are considerably dim. We know small votive mirrors decorated with circular holes or small, embossed humps along the edge from Peloponnesian sanctuaries in the Archaic period. However these turn up solely in the Archaic strata and are not to be found in later periods therefore there is no direct contact with the Roman pieces. ${ }^{27}$ The type is usually dated to the 1 st and 2 nd centuries $\mathrm{AD}$ but it is important to note that this is only the period when the pieces were buried as there is no information about when they were produced and how long they had been in use. The dating is only possible based on the accompanying datable finds or the stratigraphic data. For the lack of these K. Roth-Rubi made an attempt to make a relative chronology based on stylistic criteria. She compared the Italian and mainly Germanic mirrors that could be attached securely to absolute dates or they were found in datable burial complexes, and pointed out that the holes on the pieces from the 2nd century AD are situated closer to the center of the mirror plate and leave a wider band between the decoration elements and the edge than the ones from the 1 st century $\mathrm{AD} .{ }^{28}$ By these criteria the mirrors could be classified into a relative typological-chronological row. The method supposes that the mirrors were produced and buried in the same period, and that they were used only by a single generation. However, even if mirrors are frequent burial finds in this period, there is no information about e.g. which owner they were buried together with. It is possible that a mirror with a border of holes with the characteristic features from the 2nd century AD was produced at the same time as pieces of other character but was buried only after a longer period of usage. Therefore dating the mirrors on the basis of Roth-Rubi's criteria, without data on find circumstances, is slightly problematic. Regarding the Pannonian mirrors from datable find complexes the stylistic tendency determined by Roth-Rubi is not traceable, there is even a precedent that points to the opposite: on a mirror found in a burial mound at Felsőcikola from the Trajanic-Hadrianic period the holes are definitely closer to the egde than on other pieces from burials that belong to a villa rustica in Zanat used in the period from the Flavian era to reign of Traianus. In Pannonia no examples of mirrors with a border of hole are

25 Roth-Rubi 1974, 35.

26 Loyd Morgan 1981, 49.

27 Roth-Rubi 1974, 35.

28 Roth-Rubi 1974, 35. 
known from datable find contexts prior to the Flavian period, and the latest presence of the type is the second part of the 2nd century AD. The mirrors themselves show no spectacular stylistic differences during this interval.

For the time being, the workshops manufacturing examples of this type are unknown. RothRubi assumes the existence of a central workshop shifting places at times, ${ }^{29}$ but it is more likely that various local centres existed ${ }^{30}$ the products of which were spread in a certain region. The first workshops that produced this mirror type came into existence in the 1st century AD in Italy and diffused gradually toward the North. ${ }^{31}$ The earliest examples were of a very representative workmanship made from silver, e.g. the most celebrated finds from Pompeii or Herculaneum and Boscoreale. According to Plinius the first mirror in silver was made by Pasiteles in the time of Pompeius Magnus (Plin., Nat. Hist. XXXIII, 130). The source does not tell what this mirror looked like, but it is possible that it could have been the prototype of the mirror discs decorated with a border of holes. Based on this information the mirror type may have been produced since the second half of the 1st century BC. The earliest example from the provinces, found in Nørre Broby, can be dated between 0-40 AD. This piece is already similar to the later provincial ones: simple and schematic. The provincial workshops came into existence by the northward settling of subsidiaries of workshops in Italy and Gallia Cisalpina or the local bronze workshops started to produce the type on the basis of examples transported there from Italy or Gallia through migration or commerce.

\section{Mirror Handles (Cat. 49-56)}

The Roman mirror handles are easily recognizable by their specific form. Fragments in the collection presented in this paper belong to the group of simple rod-shape handles or a more complex handle type consisting of baluster-formed elements. Up to this day, no other type of vertical mirror handles is known from Pannonia.

Both handle-forms have a three-branched head with two small arms to hold the mirror disc and a support to which the disc is soldered. The disc support is leaf-shaped or triangleformed with rounded-off corners, the side arms could be tiered in form. The construction of the head is always the same: the front side leaning to the mirror disc's reverse side is bossed, the backside, which supports the reflecting side, is flat with a fringe in line with the side arms' upper edges. The mirror disc is sitting on this fringe, while it is supported by the side arms and the disc-support arm. The grip may be a simple rod or it may consist of two or three, rarely four baluster-like elements separated by collars. The end of the grip is a terminal knob. The size of the elements is rarely uniform; usually the upper ones are longer then the lower one. Their cross-section is usually bevelled oval or rhombic, rarely regular round in shape. In the case of some examples another rib can be observed beneath the threebranched head, imitating one more collar. The size of the handles is varied; the larger ones are usually of higher quality. These handle-types belong to hand mirrors decorated with a border of holes (group VI) or decorated with turned lines (group V) or simple disc mirrors (group II). In the case of handles found separately it cannot be determined which handle belonged to which type of hand mirrors, because there are no specific criteria, moreover the 
dimensions are not relevant because a relatively small handle could belong to a large mirror disc. There is no information about how exactly the handles were fixed to the disc: with soldering, with welding, or with cementation. Considering the number of separated handles, the method did not result in a very stable joint.

\section{Unidentifiable Fragments (Cat. 57-88)}

There are numerous fragments in the collection that are broken from the inner part of mirror discs, and do not have specific features to help to determine which type they belonged to. There are 13 fragments decorated with concentric turned lines (Cat. 57-69). These belong to disc mirrors, the turned concentric decoration is the specific feature of mirror discs with a border of holes (group VI) and turned concentric lines (group V). In the case of the other small, undecorated mirror fragments the difference between the design of the front side and the backside could be the base to determine which mirror types do the fragments belong to. The unfinished side is only typical to the undecorated disc (group II) or the rectangular mirrors (group I), based on this feature the Cat. 73-76, 79-80, 85-88. fragments originate from examples of these mirror types. If we cannot observe these characteristic features on the fragments, their type is already indefinable.

The mirror fragments are made of bronze, there is just one small, undecorated piece in silver (Cat. 87) According to metal analyses the main material of the Roman mirrors is a high tin bronze alloy (with 19-25\% tin) which is austere and hard, and by polishing it becomes deceivingly similar to silver. ${ }^{32}$ Another type of raw material was also used for casting mirrors: a low tin bronze alloy. The surface of the pieces made of this material was tinned for the analogous effect. ${ }^{33}$ This silvery surface caused a misconception in many publications: the majority of mirrors are described as being produced of silvered bronze. Thanks to the permanent polishing the mirror metal is equally reflective; there is no need for a silver coating, which may be worn away by the continuous polishing and cleaning procedures. ${ }^{34} \mathrm{~K}$. Kelbert published results of the only metal analyses on finds from Pannonia. X-ray fluorescence analyse was used to examine eight fragments. All of the fragments are made of high tin bronze alloy, where the proportion of tin always reaches $25 \%$. An additional tin coating on the surface was revealed only in one case when a $29,5 \%$ and $53,3 \%$ tin concentration was measured on the visibly different front and reverse side.

The mirrors from the collection are fragmentary, but they are in a relatively good condition. Though they are corroded and patinated, no sings of melting, blistering-off and deformation that would refer to burning could be observed except for a single case (Cat. 66). This is of high importance since bronze mirrors with traces of burning usually turn up in cremation burials from the early imperial period in Pannonia. The fragmentary state of the objects and the lack of the above mentioned features could refer to the fact that the metal collector despoiled settlements rather than cemeteries. 


\section{Catalogue}

Cat. 1. Bronze mirror fragment (Fig. 1.1, 7.1)

Inv. no. MNM RR 2011.2.12.

Fragment of a rectangular mirror with rounded-up corners. Elaboration of the two sides is different: the corroded and patinated front side is polished with a dark-grey silvery surface, the reverse is unfinished and matte. The edge is moderately bevelled.

$2.8 \times 3.5 \times 0.18 \mathrm{~cm}$

Cat. 2. Bronze mirror fragment (Fig. 1.2)

Inv. no. MNM RR 2011.2.18.

Fragment of a rectangular mirror with rounded-up corners. Elaboration of the two sides is different: the front side is polished, the reverse is unfinished and matte. The edge is unfinished.

$3.4 \times 1.6 \times 0.1 \mathrm{~cm}$

Cat. 3. Bronze mirror fragment (Fig. 1.3)

Inv. no. MNM RR 2011.2.98.

Fragment of a rectangular mirror. There is no difference between the two sides' elaboration. Both are patinated, corroded.

$2.1 \times 1.2 \times 0.1 \mathrm{~cm}$

Cat. 4. Bronze mirror fragment (Fig. 1.4)

Inv. no. MNM RR 2011.2.45.

Fragment of a rectangular mirror. There is no difference between the two sides' elaboration, both are corroded and patinated. The edge is tailed away and bevelled.

$2.4 \times 1.2 \times 0.2 \mathrm{~cm}$

Cat. 5. Bronze mirror fragment (Fig. 1.5)

Inv. no. MNM RR 2011.2.15.

Fragment of a rectangular mirror. Elaboration of the two sides is different: the front side is polished, the reverse is unfinished and matte. Moderately convex, patinated.

$2.8 \times 1.2 \times 0.2 \mathrm{~cm}$

Cat. 6. Bronze mirror fragment (Fig. 1.6)

Inv. no. MNM RR 2011.2.83.

Fragment of a rectangular disk mirror. Elaboration of the two sides is different: the front side is polished, the reverse is unfinished and matte. The edge is unfinished. Moderately patinated.

$2.3 \times 1.5 \times 0.1 \mathrm{~cm}$
Cat. 7. Bronze mirror fragment (Fig. 1.7)

Inv. no. MNM RR 2011.2.54.

Fragment of a rectangular mirror. Elaboration of the two sides is different: the front side is polished, the reverse is unfinished and matte. Moderately patinated.

$1.5 \times 2.3 \times 0.18 \mathrm{~cm}$

Cat. 8. Bronze disc mirror fragment (Fig. 1.8, 7.2) Inv. no. MNM RR 2011.2.8.

Fragment of an undecorated disk mirror. Moderately convex, both sides are in the same quality: dark-grey, matte, slightly corroded. The edge is tapering off and unfinished.

$7.7 \times 5.8 \times 0.1 \mathrm{~cm}$

Cat. 9. Bronze disc mirror fragment (Fig. 1.9)

Inv. no. MNM RR 2011.2.75.

Fragment of an undecorated mirror. Moderately convex. Both sides are the same: darkgrey, matte, strongly corroded, patinated and melted. Thickness is uneven.

$5.9 \times 4.2 \times 0.3 \mathrm{~cm}$

Cat. 10. Bronze disc mirror fragment (Fig. 1.10, 7.3)

Inv. no. MNM RR 2011.2.22.

Fragment of an undecorated disc mirror. The reflecting side is polished with a glossy, grey, silvery surface, the reverse is unfinished and mat. The edge is thickened and bevelled.

$3.3 \times 2 \times 0.1-0.2 \mathrm{~cm}$

Cat. 11. Bronze disc mirror fragment (Fig. 1.11)

Inv. no. MNM RR 2011.2.21.

Fragment of an undecorated disc mirror. Moderately convex, very thin. The reflecting side is polished with glossy black surface, slightly patinated, reverse side is unfinished.

$2.4 \times 1.6 \times 0.08 \mathrm{~cm}$

Cat. 12. Bronze disc mirror fragment (Fig. 1.12)

Inv. no. MNM RR 2011.2.73.

Fragment of an undecorated disc mirror. elaboration of both sides is similar: matte, slightly corroded, patinated.

$3.1 \times 1.5 \times 0.2 \mathrm{~cm}$ 
Cat. 13. Bronze disc mirror fragment (Fig. 1.13)

Inv. no. MNM RR 2011.2.94.

Fragment of an undecorated disc mirror. The edge is bevelled and unfinished. The reflecting side is polished with a glossy silver-like surface, the other side is unfinished and matte. $1.5 \times 2 \times 0.1 \mathrm{~cm}$

Cat. 14. Bronze disc mirror fragment (Fig. 2.14) Inv. no. MNM RR 2011.2.41.

Fragment of an undecorated disc mirror. Moderately convex, the reflecting side is polished, glossy black in colour; the reverse side is matte and unfinished. The edge is unfinished as well. $2.4 \times 2 \times 0.1 \mathrm{~cm}$

Cat. 15. Bronze disc mirror fragment (Fig. 2.15)

Inv. no. MNM RR 2011.2.59.

Fragment of an undecorated disc mirror. The reflecting side is polished, glossy black in colour; the reverse side is matte and unfinished.

$2 \times 0.9 \times 0.1 \mathrm{~cm}$

Cat. 16. Bronze disc mirror fragment (Fig. 2.16)

Inv. no. MNM RR 2011.2.97.

Fragment of an undecorated disc mirror. Moderately convex, the reflecting side is polished, silvery, the reverse side is matte and unfinished. Slightly patinated, corroded and melted. $4.4 \times 2.2 \times 0.1 \mathrm{~cm}$

Cat. 17. Bronze disc mirror fragment (Fig. 2.17)

Inv. no. MNM RR 2011.2.49.

Fragment of an undecorated mirror. Very thin, one side is polished, the other side is unfinished and matte.

$2 \times 2.2 \times 0.1 \mathrm{~cm}$

Cat. 18. Bronze disc mirror fragment (Fig. 2.18)

Inv. no. MNM RR 2011.2.78.

Fragment of an undecorated disc mirror. The edge is unfinished, one side is matte and unfinished, the other side is polished. Slightly patinated.

$1.8 \times 2.2 \times 0.1 \mathrm{~cm}$

Cat. 19. Bronze disc mirror fragment (Fig. 2.19, 7.4)

Inv. no. MNM RR 2011.2.19.

Fragment of a disc mirror, decorated on the reverse side with two lathe turned concentric lines $0.5 \mathrm{~cm}$ from the edge. Slightly convex, both sides are polished, dark grey, glossy. The edge is thickened and rounded off. Slightly patinated in a little patch.

$4.1 \times 2.4 \times 0.15 \mathrm{~cm}$

Cat. 20. Bronze disc mirror fragment (Fig. 2.20)

Inv. no. MNM RR 2011.2.96.

Fragment of a disc mirror decorated with a lathe turned concentric line cca. $0.5 \mathrm{~cm}$ from the edge. Both sides are dark grey, polished and glossy. Moderately convex, patinated and corroded.

$2 \times 2.4 \times 0.15 \mathrm{~cm}$

Cat. 21. Bronze disc mirror fragment (Fig. 2.21)

Inv. no. MNM RR 2011.2.24.

Fragment of a disc mirror decorated with a lathe turned incised concentric line along the edge. Both sides are dark grey and polished. The edge is rounded off, slightly thickened and bent back. The disc is strongly tapering off towards the centre.

$2.4 \times 1.1 \times 0.1 \mathrm{~cm}$

Cat. 22. Bronze disc mirror fragment (Fig. 2.22)

Inv. no. MNM RR 2011.2.46.

Fragment of a disc mirror, one side is polished with glossy, dark grey surface, decorated with a lathe turned concentric line along the edge, the other side seems to be unfinished. The disc is strongly tapering off towards the centre.

$3.6 \times 0.9 \times 0.1-0.08 \mathrm{~cm}$

Cat. 23. Bronze disc mirror fragment (Fig. 2.23, 7.6)

Inv. no. MNM RR 2011.2.10.

Fragment of a disc mirror decorated with incised geometric patterns. Moderately convex, both sides are dark-grey, polished and glossy. The backside is decorated with dot-and-circle patterns in a strip that is surrounded by one or two incised concentric circles along the edge. The edge is thickened and rounded off. $4.9 \times 3 \times 0.2-0.1 \mathrm{~cm}$

Cat. 24. Bronze disc mirror fragment (Fig. 2.24, 7.7)

Inv. no. MNM RR 2011.2.100.

Fragment of a disc mirror decorated with incised geometric patterns. On the reverse side, a double lathe turned concentric line runs along the rounded off, thickened edge. Closer to the centre three dot-and-circle patterns arranged in a triangle form can be seen. Also the reflecting 
side is decorated with two narrow concentric circles by the side of the edge. Both sides are dark grey in colour, polished and glossy. Slightly patinated in patches.

$3.3 \times 1.7 \times 0.1-0.11 \mathrm{~cm}$

Cat. 25. Bronze disc mirror fragment (Fig. 2.25, 7.9) Inv. no. MNM RR 2011.2.79.

Fragment of a disc mirror decorated with a lathe turned concentric line and a dot-and-circle motif on the reverse side. Both sides are polished and dark grey in colour. Thickness is uneven.

$2.1 \times 1.5 \times 0,1-0.2 \mathrm{~cm}$

Cat. 26. Bronze disc mirror fragment (Fig. 2.26, 7.82)

Inv. no. MNM RR 2011.2.82.

Fragment of a disc mirror decorated with incised geometric patterns. The edge is thickened and rounded off, the disc is moderately convex, both sides are polished, glossy, silvery. On the reverse side, two incised concentric circles and closer to the centre, five dot-and-circle patterns arranged in two lines can be seen. Slightly patinated.

$2.4 \times 1.5 \times 0.2-0.12 \mathrm{~cm}$

Cat. 27. Bronze disc mirror fragment (Fig. 2.27, 7.58)

Inv. no. MNM RR 2011.2.58.

Fragment of a disc mirror decorated with incised geometric patterns. Moderately convex, both sides are polished, dark grey in colour. On the reverse side radiate, straight lines spring from one point of the edge, where small sections of a concentric circle are also visible.

$2.9 \times 2 \times 0.15 \mathrm{~cm}$

Cat. 28. Bronze disc mirror fragment (Fig. 2.28, 7.11)

Inv. no. MNM RR 2011.2.14.

Fragment of a disc mirror decorated with incised geometric patterns. On the reverse side a part of a rosette filled with bevelled lines and dot-and-circle motifs are arranged into several fields separated by concentric circles. Both sides are polished, with glossy, grey surface. Slightly patinated.

$3.8 \times 1.5 \times 0.2 \mathrm{~cm}$

Cat. 29. Bronze disc mirror fragment (Fig. 2.29)

Inv. no. MNM RR 2011.2.64.

Fragment of a disc mirror decorated with incised geometric patterns. Both sides are polished, glossy, dark grey in colour. A leaf-like motif filled with bevelled lines can be seen on the reverse side. Strongly patinated, moderately convex.

$2.5 \times 1.7 \times 0.1 \mathrm{~cm}$

Cat. 30. Bronze disc mirror fragment (Fig. 3.30)

Inv. no. MNM RR 2011.2.102.

Fragment of a disc mirror decorated with lathe turned concentric ribs and lines on the reverse side. The reflecting side is undecorated; both sides are polished and silvery. Slightly corroded, patinated.

$3.3 \times 1.4 \times 0.2 \mathrm{~cm}$

Cat. 31. Bronze disc mirror fragment (Fig. 3.31, 7.5)

Inv. no. MNM RR 2011.2.51.

Fragment of a disc mirror decorated with lathe turned concentric circles on both sides. Corroded, patinated.

$2.8 \times 1.1 \times 0.1 \mathrm{~cm}$

Cat. 32. Bronze disc mirror fragment (Fig. 3.32, 8.12)

Inv. no. MNM RR 2011.2.9+2011.2.86.

Two related fragments of a mirror disc decorated with a border of holes and lathe turned concentric circles on both sides. Three turned circles can be seen on the reverse side while on the reflecting side there is a single circle along the border of holes. Both sides are polished, dark grey in colour, corroded and patinated. Thickness is uneven; the middle part and the edge is somewhat thickened.

Reconstructed diameter: $12 \mathrm{~cm}$, thickness: 0.15 $\mathrm{cm}$

Cat. 33. Bronze disc mirror fragment (Fig. 3.33, 8.13)

Inv. no. MNM RR 2011.2.13.

Fragment of a mirror disc decorated with a border of holes an lathe turned concentric circles on both sides. Polished, glossy, silvery grey in colour. The middle part is thicker than in other parts.

$4 \times 2.5 \times 0.15-0.1 \mathrm{~cm}$

Cat. 34. Bronze disc mirror fragment (Fig. 3.34)

Inv. no. MNM 2011.2.11.

Fragment of a mirror disc decorated with a border of holes and lathe turned concentric circles on both sides. Moderately convex, three concentric circles can be seen on the reverse side while a single line runs along the holes on the reflecting side. Corroded and patinated. $4.4 \times 2.3 \times 0.2 \mathrm{~cm}$ 
Cat. 35. Bronze disc mirror fragment (Fig. 3.35, 8.14) Inv. no. MNM RR 2011.2.89.

Fragment of a mirror disc decorated with a border of holes. Along the edge two holes can be seen at a considerable distance from each other (place of handle?). Lathe turned concentric circles decorate both sides, on the reflecting side they run along the border of holes. Thickness is uneven, thickening towards the edge. Patinated in patches.

$2.7 \times 1.9 \times 0.15 \mathrm{~cm}$

Cat. 36. Bronze disc mirror fragment (Fig. 3.36) Inv. no. MNM RR 2011.2.56.

Fragment of a mirror disc decorated with a border of holes and lathe turned concentric circles on both sides. Both sides are grey, silvery, glossy, strongly patinated.

$4.7 \times 3.6 \times 0.2 \mathrm{~cm}$

Cat. 37. Bronze disc mirror fragment (Fig. 4.37) Inv. no. MNM RR 2011.2.76.

Fragment of a mirror disc decorated with a border of holes and lathe turned concentric circles on both sides. The edge is strongly frayed; small parts of the holes remain. Both sides are silvery grey, polished, glossy, there is a single turned circle on the reflecting side and three on the reverse side. Slightly patinated.

$4.9 \times 2.5 \times 0.1 \mathrm{~cm}$

Cat. 38. Bronze disc mirror fragment (Fig. 4.38) Inv. no. MNM RR 2011.2.23.

Fragment of a mirror disc decorated with a border of holes and lathe turned concentric circles on both sides. Dark grey in colour, polished, glossy. Slightly patinated in patches.

$3.1 \times 2 \times 0.1 \mathrm{~cm}$

Cat. 39. Bronze disc mirror fragment (Fig. 4.39) Inv. no. MNM RR 2011.2.91.

Fragment of a mirror disc decorated with a border of holes and lathe turned concentric circles on both sides. Silvery grey in colour, polished, but strongly patinated and corroded.

$3.3 \times 3 \times 0.2 \mathrm{~cm}$

Cat. 40. Bronze disc mirror fragment (Fig. 4.40)

Inv. no. MNM RR 2011.2.16.

Fragment of a mirror disc decorated with a border of holes and lathe turned concentric circles on both sides. Dark grey in colour, polished, glossy, but strongly corroded and patinated.

$3 \times 1.8 \times 0.2 \mathrm{~cm}$
Cat. 41. Bronze disc mirror fragment (Fig. 4.41)

Inv. no. MNM RR 2011.2.69.

Fragment of a mirror disc decorated with a border of holes and lathe turned concentric circles on both sides. Glossy, dark grey, silvery surface, but strongly corroded and patinated.

$3.3 \times 2.4 \times 0.2 \mathrm{~cm}$

Cat. 42. Bronze disc mirror fragment (Fig. 4.42)

Inv. no. MNM RR 2011.2.62.

Fragment of a mirror disc decorated with a border of holes and lathe turned concentric circles on both sides. Grey in colour, polished, glossy, but strongly patinated and corroded.

$3.7 \times 1.4 \times 0.15 \mathrm{~cm}$

Cat. 43. Bronze disc mirror fragment (Fig. 4.43)

Inv. no. MNM RR 2011.2.99.

Fragment of a mirror disc decorated with a border of holes. Both sides are dark grey in colour, glossy, polished, but strongly corroded and patinated. Densely set lathe turned concentric circles decorate the reverse side.

$2.7 \times 3.4 \times 0.3 \mathrm{~cm}$

Cat. 44. Bronze disc mirror fragment (Fig. 4.44)

Inv. no. MNM RR 2011.2.71.

Fragment of a mirror disc decorated with a border of holes. Silvery grey in colour, both sides polished, glossy. The reverse side is decorated with lathe turned concentric circles, the other side is undecorated.

$2.7 \times 1.6 \times 0.1 \mathrm{~cm}$

Cat. 45. Bronze disc mirror fragment (Fig. 4.45)

Inv. no. MNM RR 2011.2.87.

Fragment of a mirror disc decorated with a border of holes and lathe turned concentric circles. Black in colour, with a glossy, reflecting surface on both sides. Patinated in patches.

$2.5 \times 1.8 \times 0.12-0.1 \mathrm{~cm}$

Cat. 46. Bronze disc mirror fragment (Fig. 4.46)

Inv. no. MNM RR 2011.2.42.

Fragment of mirror disc decorated with a border of holes and lathe turned concentric circles on both sides. Dark grey in colour, polished, with a glossy surface. The disc is tapering off towards the centre. Slightly patinated.

$1.7 \times 1.5 \times 0.15-0.12 \mathrm{~cm}$

Cat. 47. Bronze disc mirror fragment (Fig. 4.47)

Inv. no. MNM RR 2011.2.50. 
Fragment of a mirror disc decorated with a border of holes and lathe turned concentric circles on both sides. Polished, dark grey in colour. Patinated in small patches.

$2.9 \times 1.3 \times 0.15 \mathrm{~cm}$

Cat. 48. Bronze disc mirror fragment (Fig. 4.48)

Inv. no. MNM RR 2011.2.61.

Fragment of a mirror disc decorated with a border of holes and lathe turned concentric circles. Both sides are matte, unfinished. Circular scratches are visible on the entire surface of the reflecting side.

$2.2 \times 1.7 \times 0.1 \mathrm{~cm}$

Cat. 49. Bronze mirror handle fragment (Fig. 4.49)

Inv. no. MNM RR 2011.2.113.

Fragment of a grip-type, possibly complex, vertical handle tapering off towards the end with a three-branched head to support the mirror disc. Oval in cross-section. Slightly patinated.

$6.6 \times 3 \times 0.6 \mathrm{~cm}$

Cat. 50. Bronze mirror handle fragment (Fig. 4.50)

Inv. no. MNM RR 2011.2.108.

Fragment of a grip-type, complex, vertical handle. The three-branched head is slightly convex, at the juncture of the head and the rod a horizontal rib can be seen. Oval in cross-section.

$5.9 \times 3 \times 0.5 \mathrm{~cm}$

Cat. 51. Bronze mirror handle fragment (Fig. 5.51)

Inv. no. MNM RR 2011.2.107.

Fragment of a complex vertical handle consisting of baluster-like elements separated by collars with the head to support the disc. Most part of the disc support is broken away, the side arms are fragmentary as well. At the juncture of the head and the first baluster element a short horizontal rib can be seen. Patinated.

$5.1 \times 2.7 \times 0.5 \mathrm{~cm}$

Cat. 52. Bronze mirror handle fragment (Fig. 5.52)

Inv. no. MNM RR 2011.2.115.

Fragment of a rod-type vertical handle with a three-branched head to support the disc. The head is asymmetric, the disc support is somewhat scuffed. The rod is ovoid in cross-section, at the juncture of the head and the grip a short horizontal rib can be seen. Patinated.

$4.6 \times 2.5 \times 0.5 \mathrm{~cm}$
Cat. 53. Bronze mirror handle fragment (Fig. $5.53,8.16)$

Inv. no. MNM RR 2011.2.109.

Fragment of a complex vertical handle consisting of baluster-like elements separated by ribs. The arms of the head supporting the disc are spiked and the side-arms are tiered. At the juncture of the head and the first baluster element a short, rectangular, horizontal rib can be seen. Ovoid in cross-section.

$5.3 \times 2.7 \times 0.5 \mathrm{~cm}$

Cat. 54. Bronze mirror handle fragment (Fig. 5.54)

Inv. no. MNM RR 2011.2.111.

Fragment of a rod-like vertical handle with a three-branched head to support the disc. Ovoid in cross-section, patinated.

$3.8 \times 2.2 \times 0.4 \mathrm{~cm}$

Cat. 55. Bronze mirror handle fragment (Fig. 5.55)

Inv. no. MNM RR 2011.2.110.

Fragment of a rod-like vertical handle with a three-branched head to support the disc. The major part of the disc support arm is broken away. Round in cross-section.

$4.6 \times 1.9 \times 0.5 \mathrm{~cm}$

Cat. 56. Bronze mirror handle fragment (Fig. 5.56)

Inv. no. MNM RR 2011.2.112.

Fragment of a complex vertical handle consisting of baluster like elements separated by ribs. The arms of the three-branched head are spiked, the side-arms are tiered. At the juncture of the head and the first baluster element a short, rectangular, horizontal rib can be seen. Ovoid in cross-section, corroded, patinated.

$2.4 \times 4.7 \times 0.5 \mathrm{~cm}$

Cat. 57. Bronze disc mirror fragment (Fig. 5.57)

Inv. no. MNM RR 2011.2.20.

Fragment of a mirror disc, both sides are polished. The non-reflecting side is decorated with three lathe turned concentric lines. Slightly patinated.

$3.3 \times 2.5 \times 0.15 \mathrm{~cm}$

Cat. 58. Bronze disc mirror fragment (Fig. 5.58)

Inv. no. MNM RR 2011.2.53.

Fragment of a mirror disc with an accentuated centre-point, decorated with lathe turned concentric circles. Both sides are polished, dark grey in colour but strongly corroded.

$2.8 \times 1.8 \times 0.15 \mathrm{~cm}$ 
Cat. 59. Bronze disc mirror fragment (Fig. 5.59)

Inv. no. MNM RR 2011.2.72.

Fragment of a mirror disc decorated with two lathe turned concentric circles. Dark grey in colour with glossy surface.

$3.2 \times 2.2 \times 0.15 \mathrm{~cm}$

Cat. 60. Bronze disc mirror fragment (Fig. 5.60)

Inv. no. MNM RR 2011.2.103.

Fragment of a mirror disc decorated with lathe turned concentric circles on the non-reflecting side. Slightly patinated.

$3 \times 2.5 \times 0.2 \mathrm{~cm}$

Cat. 61. Bronze disc mirror fragment (Fig. 5.61)

Inv. no. MNM RR 2011.2.33.

Fragment of a mirror disc decorated with a lathe turned concentric circle on one side. Both sides are polished, glossy, dark grey in colour. $2.4 \times 1.7 \times 0.2 \mathrm{~cm}$

Cat. 62. Bronze disc mirror fragment (Fig. 5.62)

Inv. no. MNM RR 2011.2.40.

Fragment of a disc mirror decorated with a lathe turned concentric circle on the non-reflecting side. Slightly patinated.

$2.7 \times 1.8 \times 0.2 \mathrm{~cm}$

Cat. 63. Bronze disc mirror fragment (Fig. 5.63)

Inv. no. MNM RR 2011.2.85.

Fragment of a disc mirror decorated with a lathe turned concentric circle. Both sides are polished, glossy, dark grey in colour.

$2.2 \times 1.6 \times 0.1 \mathrm{~cm}$

Cat. 64. Bronze disc mirror fragment (Fig. 5.64)

Inv. no.: MNM RR 2011.2.48.

Fragment of a disc mirror decorated with a lathe turned concentric circle. Both sides are polished, dark grey in colour, slightly patinated.

$2.9 \times 2 \times 0.15 \mathrm{~cm}$

Cat. 65. Bronze disc mirror fragment (Fig. 5.65, 8.15)

Inv. no. MNM RR 2011.2.92.

Fragment of a disc mirror. Both sides are polished, glossy, silvery. The centre of the disc has been preserved, on the reverse side there is a turned concentric circle around the centrepoint accompanied by two other incised, small, irregular circles in different sizes.

$3.6 \times 1.7 \times 0.12 \mathrm{~cm}$
Cat. 66. Bronze disc mirror fragment (Fig. 5.66)

Inv. no. MNM RR 2011.2.17.

Strongly corroded and patinated fragment of a disc mirror. Two lathe turned concentric circles can be seen on one side, the other side is completely molten.

$3.3 \times 2.7 \times 0.4 \mathrm{~cm}$

Cat. 67. Bronze disc mirror fragment (Fig. 5.67)

Inv. no. MNM RR 2011.2.32.

Fragment of a mirror disc decorated with lathe turned concentric circles. Both sides are polished, dark grey in colour, the reverse side is strongly patinated and corroded.

$2.8 \times 1.8 \times 0.12 \mathrm{~cm}$

Cat. 68. Bronze disc mirror fragment (Fig. 5.68)

Inv. no. MNM RR 2011.2.35.

Moderately convex fragment of a mirror disc decorated with incised concentric circles. Both sides are polished, dark grey in colour. Slightly patinated in patches.

$2.2 \times 1.4 \times 0.15 \mathrm{~m}$

Cat. 69. Bronze disc mirror fragment (Fig. 5.69)

Inv. no. MNM RR 2011.2.77.

Fragment of a mirror disc decorated with a lathe turned concentric circle. Thickness is uneven; thickens towards the centre. Both sides are polished, dark grey in colour, slightly patinated in patches.

$3.2 \times 1.7 \times 0.18-0.2 \mathrm{~cm}$

Cat. 70. Bronze disc mirror fragment (Fig. 5.70)

Inv. no. MNM RR 2011.2.63.

Undecorated mirror fragment, moderately convex, slightly patinated.

$2 \times 2.2 \times 0.12 \mathrm{~cm}$

Cat. 71. Bronze mirror fragment (Fig. 6.71)

Inv. no. MNM RR 2011.2.70.

Undecorated, moderately convex mirror fragment. No difference can be traced in the elaboration of the two sides.

$3.4 \times 2.4 \times 0.2 \mathrm{~cm}$

Cat. 72. Bronze mirror fragment (Fig. 6.72)

Inv. no. MNM RR 2011.2.105.

Undecorated fragment of a mirror. Both sides are finished in the same quality, slightly patinated, exfoliated.

$2.3 \times 1.6 \times 0.15 \mathrm{~cm}$ 
Cat. 73. Bronze mirror fragment (Fig. 6.73)

Inv. no. MNM RR 2011.2.31.

Fragment of a mirror disc, one size is unfinished and matte, the other side is polished. Slightly patinated in patches.

$2 \times 2.8 \times 0.12 \mathrm{~cm}$

Cat. 74. Bronze mirror fragment (Fig. 6.74)

Inv. no. MNM RR 2011.2.39.

Undecorated fragment of a mirror disc, one side is unfinished and matte, the other side is polished. Slightly patinated.

$2.7 \times 2 \times 0.2 \mathrm{~cm}$

Cat. 75. Bronze mirror fragment (Fig. 6.75)

Inv. no. MNM RR 2011.2.65.

Undecorated fragment of a disc mirror disc, one side is polished, the other side is unfinished and matte. Slightly patinated.

$2.2 \times 1.8 \times 0.1 \mathrm{~cm}$

Cat. 76. Bronze mirror fragment (Fig. 6.76)

Inv. no. MNM RR 2011.2.60.

Undecorated fragment of a mirror disc. One side is unfinished and matte, the other side is polished. Slightly convex.

$2.3 \times 1.8 \times 0.1 \mathrm{~cm}$

Cat. 77. Bronze mirror fragment (Fig. 6.77)

Inv. no. MNM RR 2011.2.66.

Undecorated fragment of a mirror disc. Both sides are finished in the same quality: matte, unpolished. Slightly corroded.

$2.2 \times 2.3 \times 0.15 \mathrm{~cm}$

Cat. 78. Bronze mirror fragment (Fig. 6.78)

Inv. no. MNM RR 2011.2.84.

Undecorated fragment of a mirror. Patinated, corroded. No difference can be traced in the elaboration of the two sides.

$2.3 \times 1.8 \times 0.2 \mathrm{~cm}$

Cat. 79. Bronze mirror fragment (Fig. 6.79)

Inv. no. MNM RR 2011.2.80.

Undecorated fragment of a mirror, one side is polished, the other side is unfinished and matte.

$1.9 \times 1.1 \times 0.1 \mathrm{~cm}$

Cat. 80. Bronze mirror fragment (Fig. 6.80)

Inv. no. MNM RR 2011.2.57.

Undecorated fragment of a mirror, one side is unfinished and matte, the other side is polished.

$1.7 \times 0.2 \times 1.5 \mathrm{~cm}$
Cat. 81. Bronze mirror fragment (Fig. 6.81)

Inv. no. MNM RR 2011.2.55.

Undecorated fragment of a mirror disc, both sides are unfinished and matte.

$2.9 \times 1.2 \times 0.1 \mathrm{~cm}$

Cat. 82. Bronze mirror fragment (Fig. 6.82)

Inv. no. MNM RR 2011.2.34.

Undecorated fragment of a mirror disc, both sides are finished in the same quality. Slightly patinated.

$1.6 \times 1.3 \times 0.15 \mathrm{~cm}$

Cat. 83. Bronze mirror fragment (Fig. 6.83)

Inv. no. MNM RR 2011.2.67.

Undecorated fragment of a mirror disc, one side is unfinished and matte, the other side is polished. Slightly patinated in patches.

$1.9 \times 1.3 \times 0.1 \mathrm{~cm}$

Cat. 84. Bronze mirror fragment (Fig. 6.84)

Inv. no. MNM RR 2011.2.74.

Undecorated fragment of a mirror disc, the reverse side is unfinished and matte, the reflecting side is polished. Thickness is uneven.

$1.9 \times 1.2 \times 0.1-0.2 \mathrm{~cm}$

Cat. 85. Bronze mirror fragment (Fig. 6.85)

Inv. no. MNM RR 2011.2.38.

Undecorated fragment of a mirror disc. One side is unfinished and matte, the other side is polished. Moderately convex, slightly patinated.

$3.6 \times 1.9 \times 0.2 \mathrm{~cm}$

Cat. 86. Bronze mirror fragment (Fig. 6.86)

Inv. no. MNM RR 2011.2.36.

Undecorated fragment of a mirror disc, both sides are finished in the same quality.

$2.7 \times 2.3 \times 0.2 \mathrm{~cm}$

Cat. 87. Silver mirror fragment (Fig. 6.87)

Inv. no. MNM RR 2011.2.81.

Undecorated fragment of a mirror disc.

$1.6 \times 1.4 \times 0.1 \mathrm{~cm}$

Cat. 88. Bronze mirror fragment (Fig. 6.88)

Inv. no. MNM RR 2011.2.27.

Undecorated fragment of a mirror disc. One side is unfinished, matte, the other side is polished.

$2.3 \times 1.6 \times 0.12 \mathrm{~cm}$ 


\section{References}

Intercisa I: Alföldi, R. M. et al. (eds.), Intercisa I. Geschichte der Stadt in der Römerzeit. Budapest 1954.

Cüppers, H. 1983: Die Römer an Mosel und Saar. Zeugnisse der Römerzeit in Lothringen, in Luxemburg, im Raum Trier und im Saarland. Mainz am Rhein.

Istenič, J. 1999: Poetovio, zahodna Grobišča II. - Poetovio, The Western Cemeteries. Catalogi et Monographiae 33. Ljubjana.

Kelbert, K. 2007: Római tükrök Savariában. Savaria 31, 172-233.

Konrad, M. 1997: Das Römische Gräberfeld von Bregenz - Brigantium. I. Die Körpergräber des 3. bis 5. fahrhunderts. München.

Krunič, S. 2000: Rimski medicinski, farmaceutski i kozmetički instrumenti na teritoriji Gornje Mezije. Beograd.

Lloyd Morgan, G. 1977a: Mirrors in Roman Britain. In: Munby, S. - Henig, M. (eds.), Roman Life and Art in Britain. A Celebration of the eightieth birthday of Jocelyn Toynbee. British Archaeological Reports 41. Oxford, 231-252.

Lloyd Morgan, G. 1977b: Two Roman Mirror from Corbridge. Britannia 8, 335-338.

Lloyd Morgan, G. 1981: The Mirrors, including a Description of the Roman Mirrors found in the Nederlands, in other Dutch Museums. Description of the Collections in the Rijkmuseum G. M. Kam at Nijmegen IX. Nijmegen.

McDonell, D. R. - Meijers, J. M. R. - Kars, H. 1995: The Composition and Micrisructure of Six Fragments of Roman Mirror from Nijmegen, the Netherlands. In: Mols, S. T. A. M. et al. (eds.), Acta of the 12th International Congress of Ancient Bronzes, Nijmegen 1992. Nijmegen, 169-178.

Meeks, N. 1995: A Technical Study of Roman Bronze Mirrors. In: Mols, S. T. A. M. et al. (eds.), Acta of the 12th International Congress of Ancient Bronzes, Nijmegen 1992. Nijmegen, 179-193.

Roth-RuBI, K. 1974: Zur Typologie römischer Griffspiegel. Bulletin des Musees Royaux d'Art et d'Histoire 6/46, 31-41.

Simonett, Ch. 1941: Tessiner Graberfelder. Ausgrabungen des Archäologischen Arbeitsdienstes in Solduno, Locarno-Muralto, Minusio und Stabio, 1936 und 1937. Basel.

TopÁL, J. 1981: The southern cemetery of Matrica (Százhalombatta-Dunafüred). Fontes Archeologici Hungariae. Budapest.

Treister, M. J. 1994: Italic and Provincial-Roman Mirrors in Eastern Europe. In: Planck, D. (ed.), Akten der 10. Internationalen Tagung über Antike Bronzen. Freiburg, 18-22. Fuli 1988. Forschungen und Berichte zur Vor- und Frühgeschichte in Baden-Würtenberg 45. Stuttgart, 417-428. 


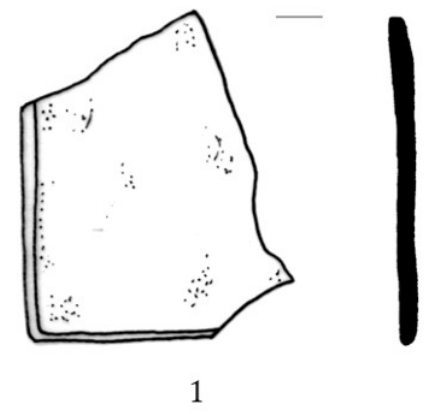

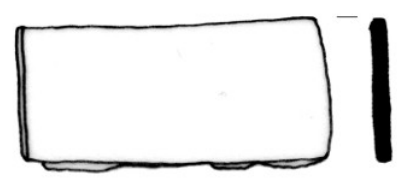

2

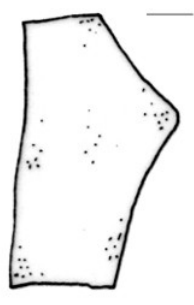

5

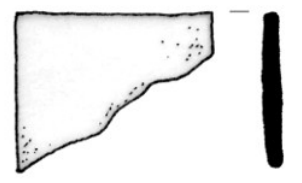

3

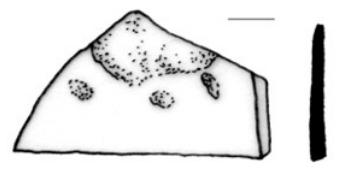

6
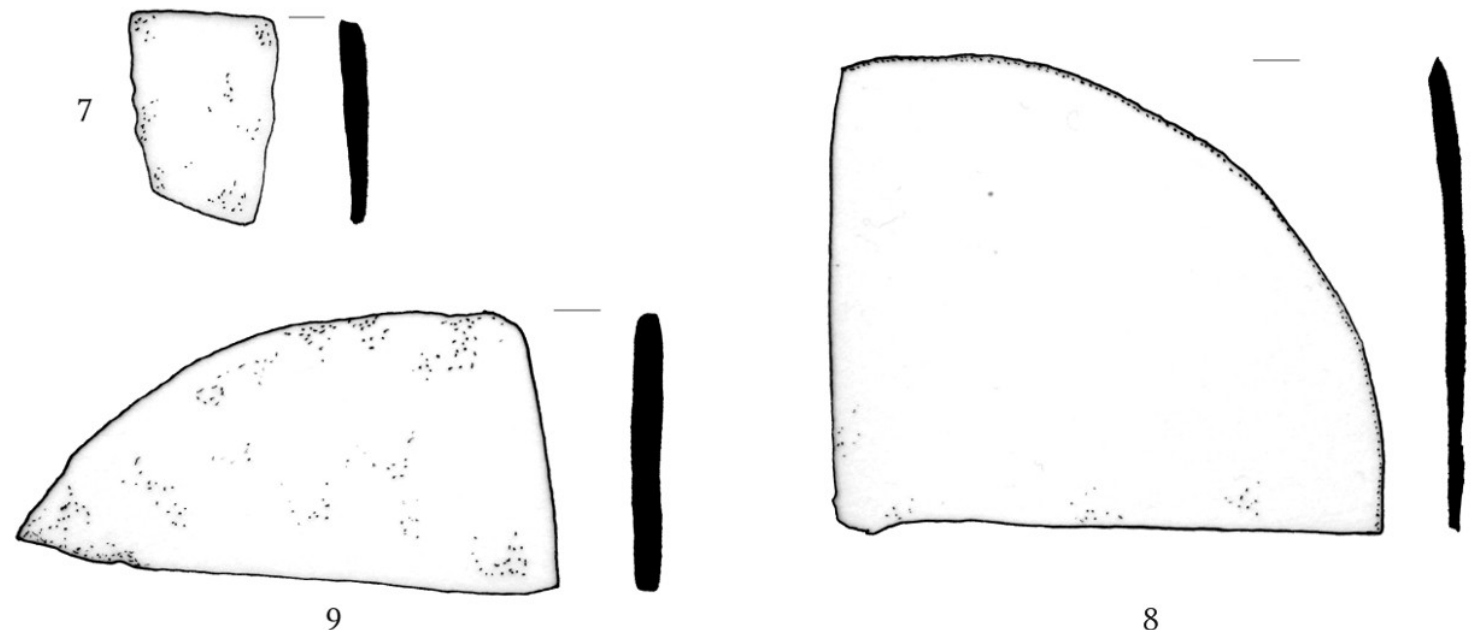

8
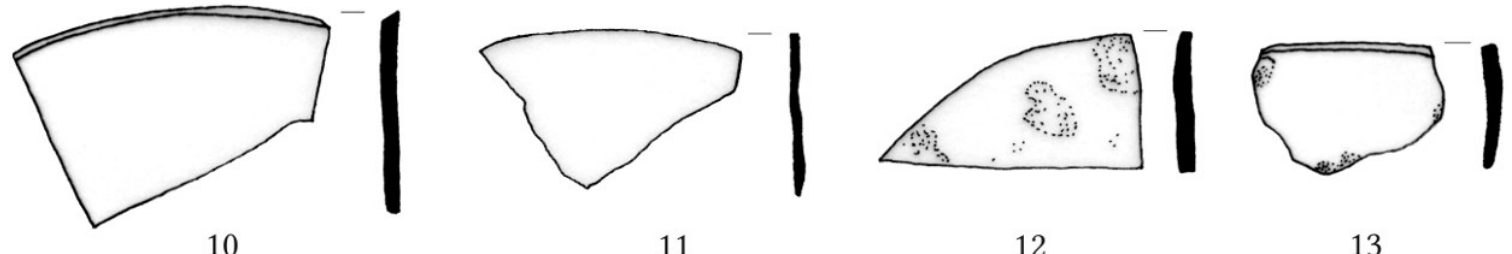

11

12

13

$5 \mathrm{~cm}$

Fig. 1. 


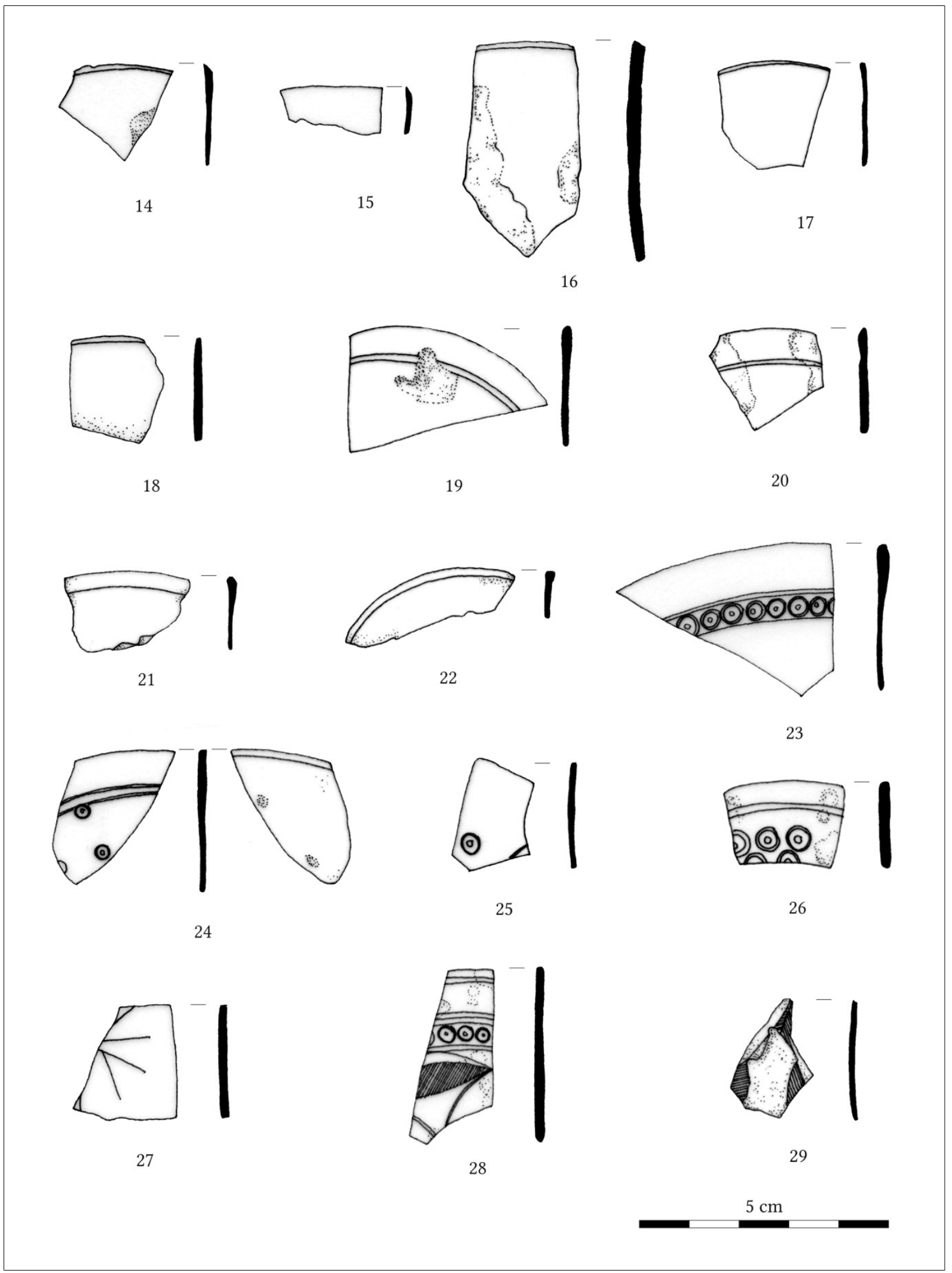

Fig. 2. 


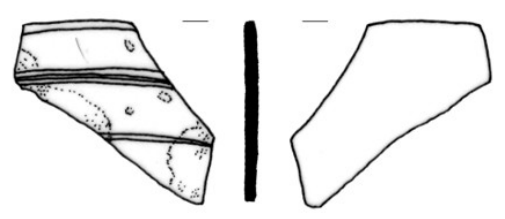

30
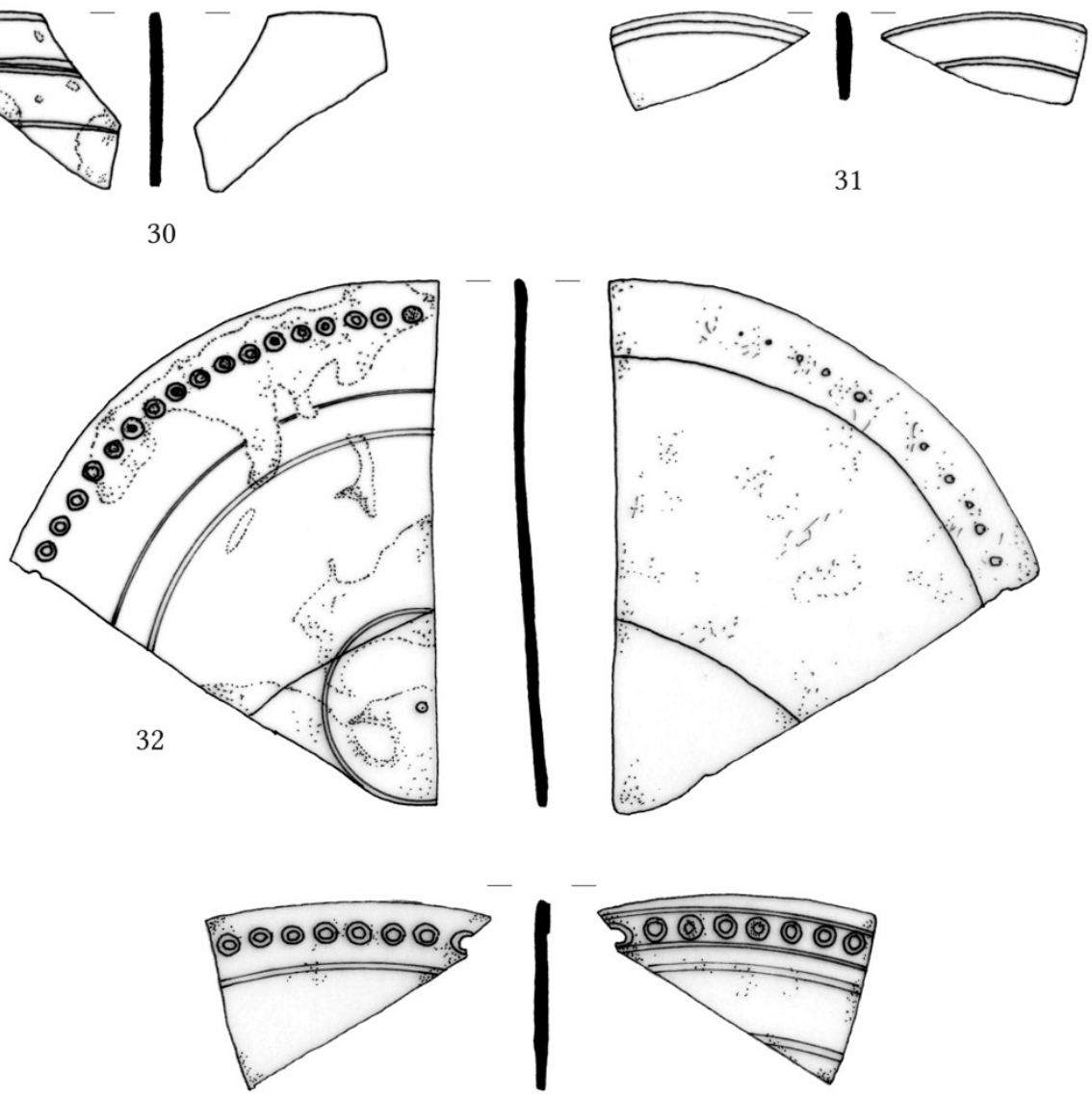

31

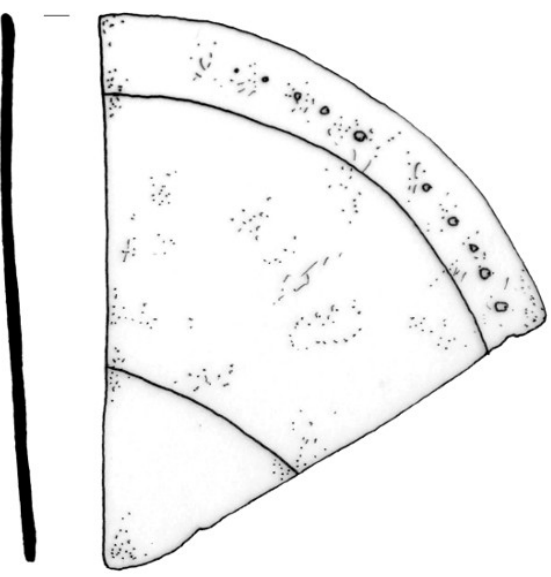

33

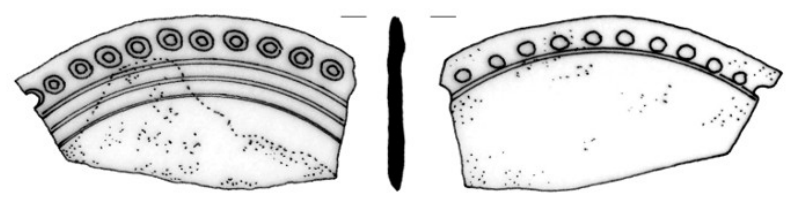

34
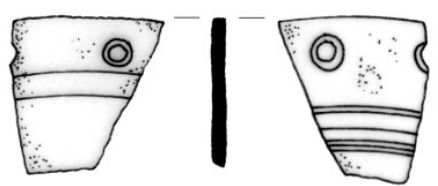

35

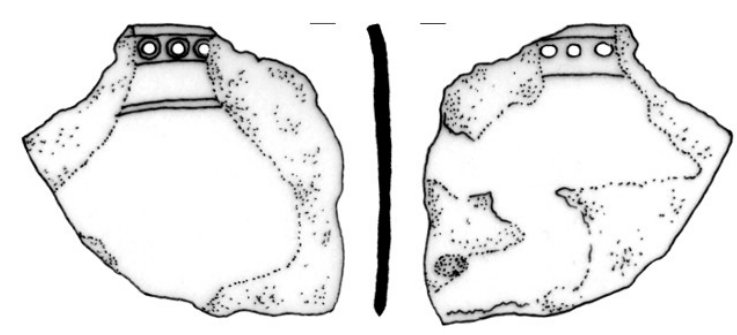

36

Fig. 3. 


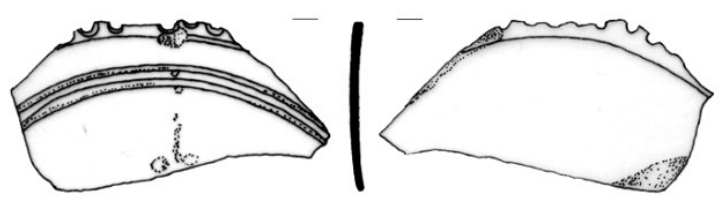

37
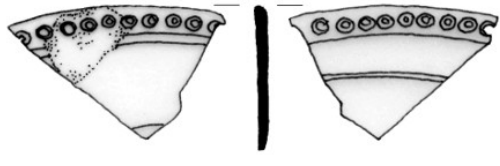

38

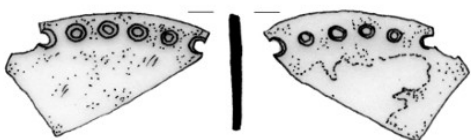

40

39

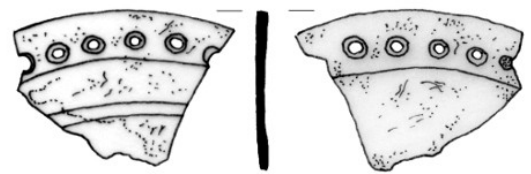

41

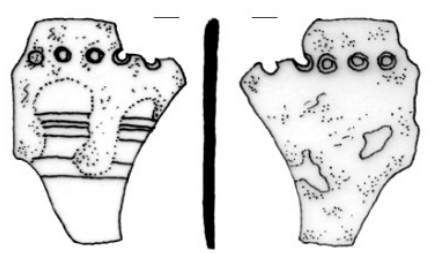

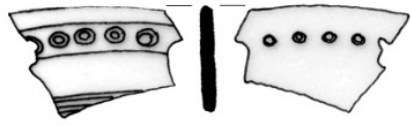

44

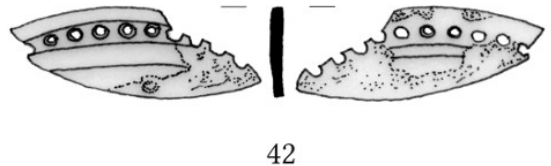

42

43

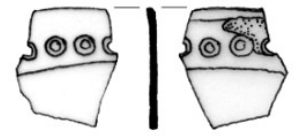

46

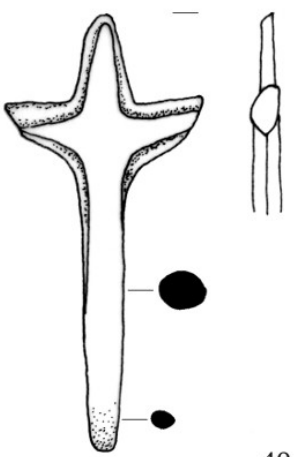

49

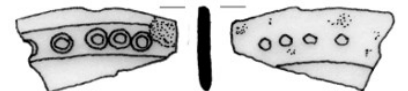

47

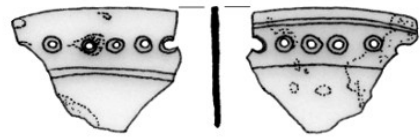

45

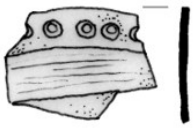

48

Fig. 4. 


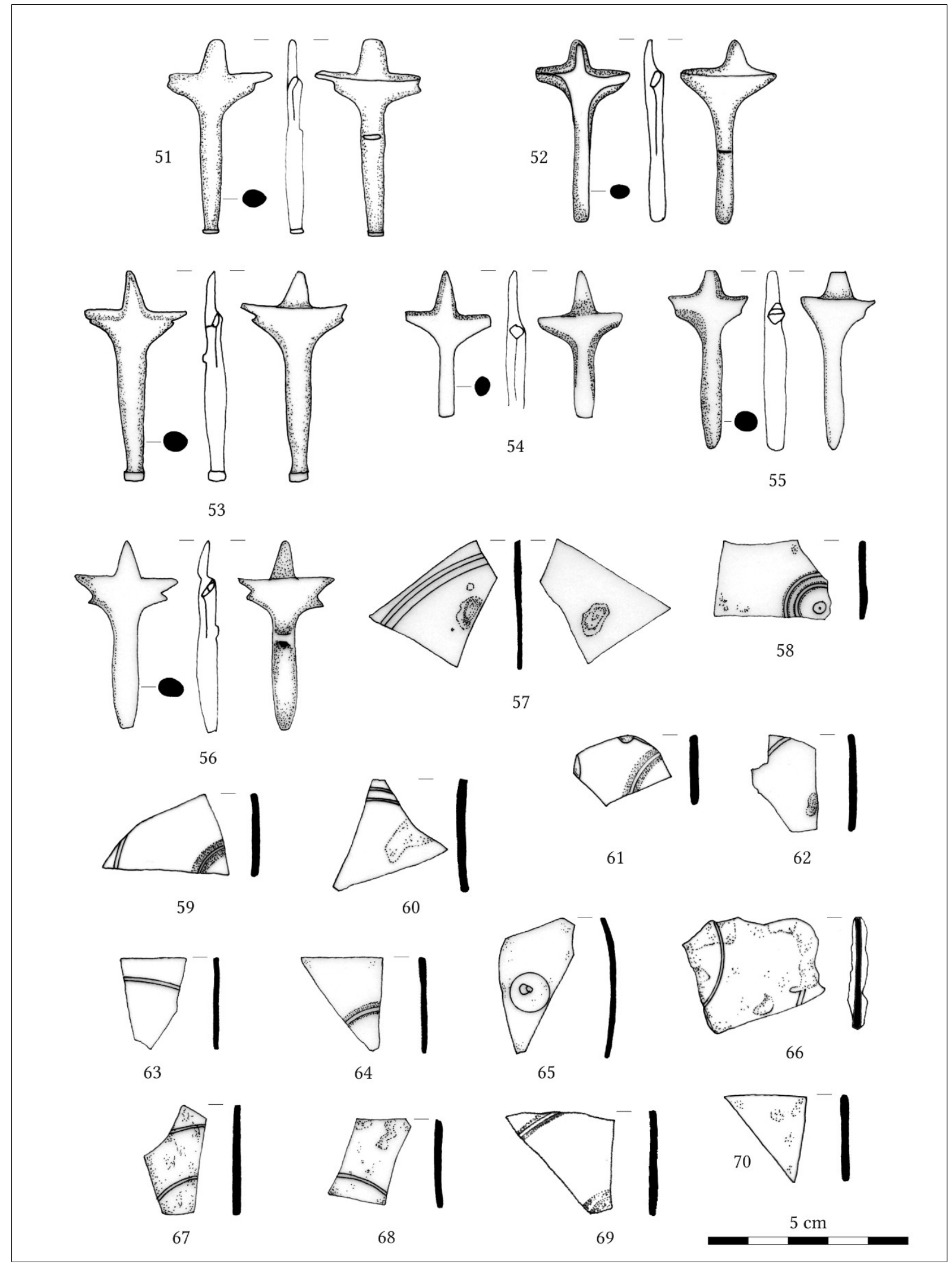

Fig. 5. 


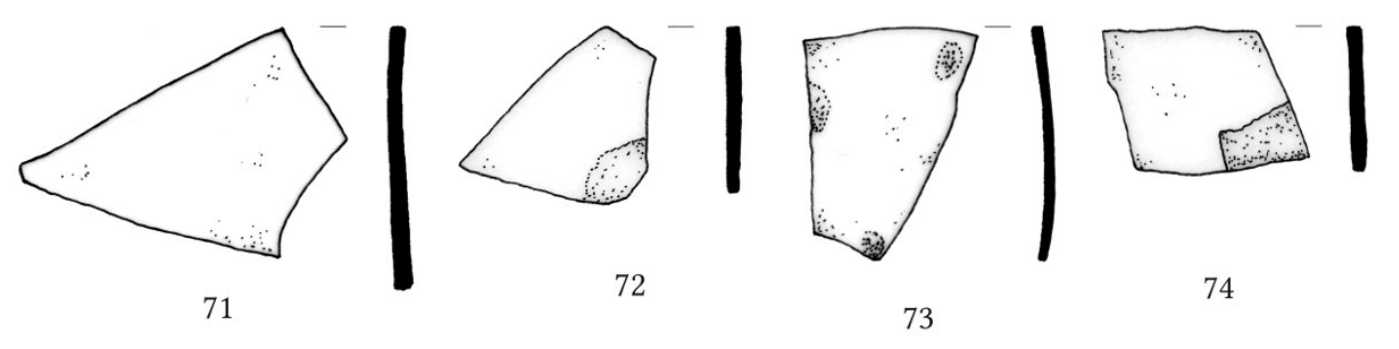

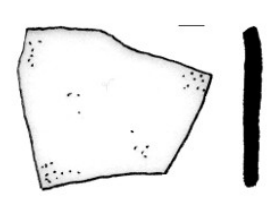

75

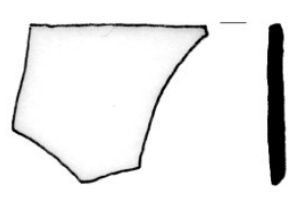

76

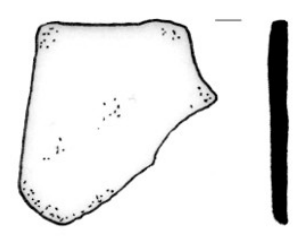

77

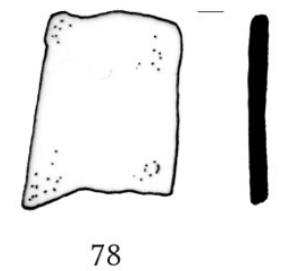

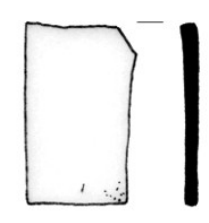

79

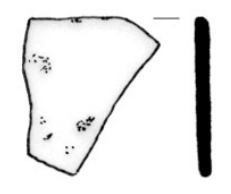

83

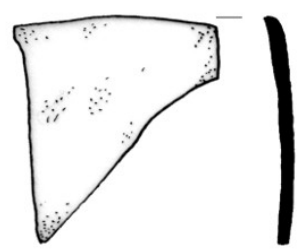

86

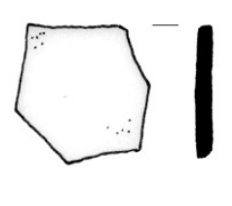

80

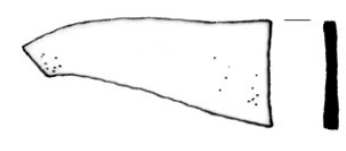

81

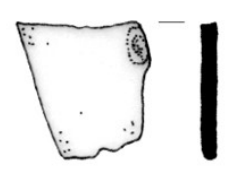

82

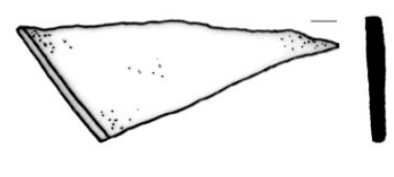

85

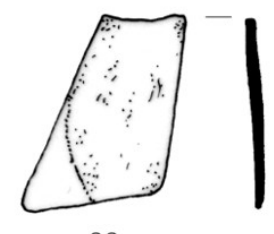

88

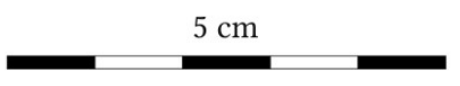

Fig. 6. 
Roman mirrors from a private collection in the Hungarian National Museum

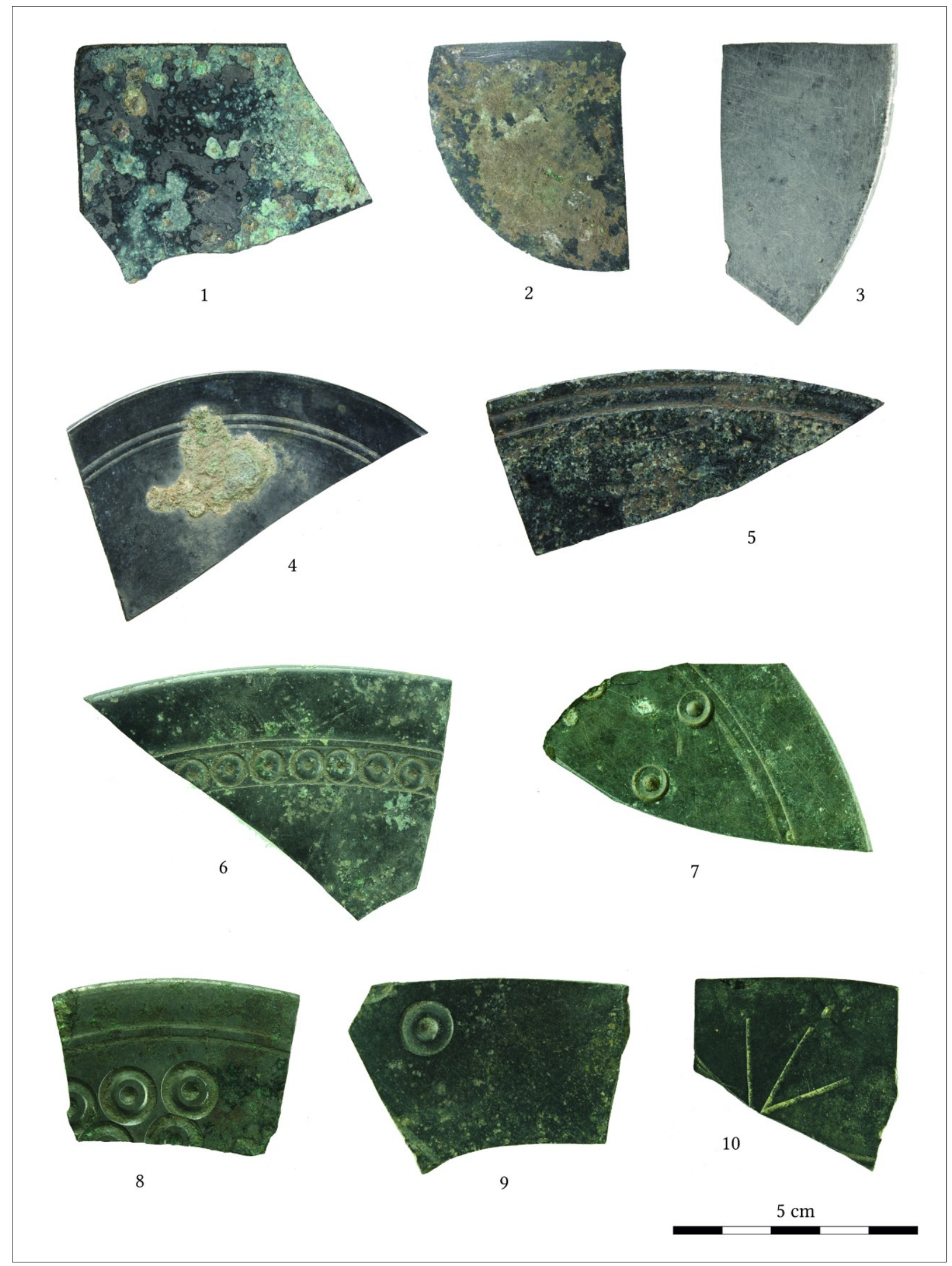

Fig. 7. 


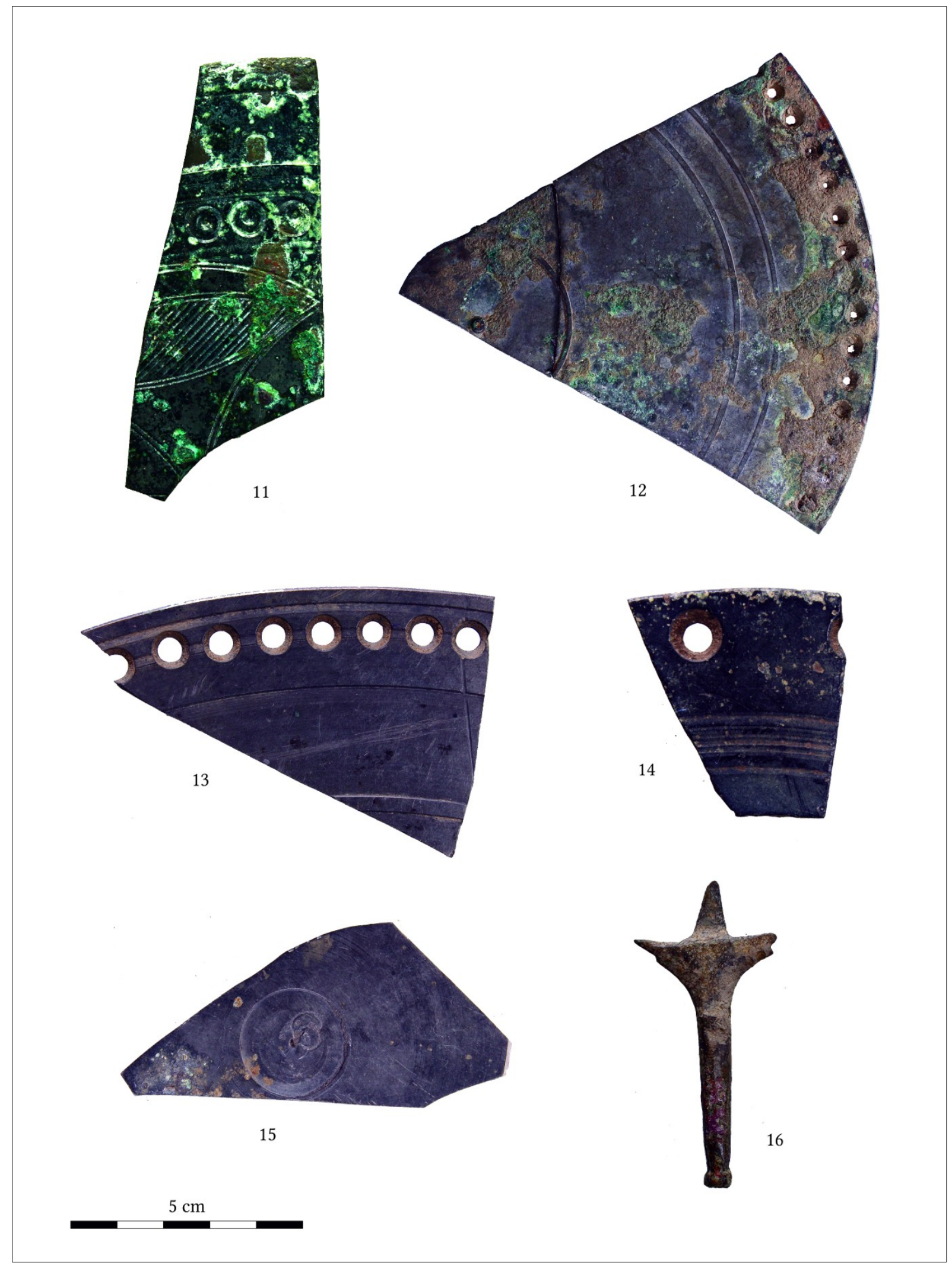

Fig. 8. 